\title{
BIOY Y SUS PRECURSORES \\ LA TRADICIÓN DE LA CIENCIA FICCIÓN EN LA NARRATIVA DE ADOLFO BIOY CASARES
}

\author{
POR \\ Mariano García \\ Universidad Católica Argentina - CONICET
}

Desde la publicación de su primera novela "oficial", La invención de Morel (1940), no faltaron lectores y críticos que señalaran en la narrativa de Adolfo Bioy Casares (1914-1999) las influencias o filiaciones literarias, filosóficas o científicas que los propios textos establecían según alusiones más o menos veladas. El primero en hacerlo, de manera notoria, fue como se sabe Jorge Luis Borges (1899-1986), por entonces interesado en dar un espaldarazo al joven amigo y en cierto modo discípulo, que contaba en su pasado con varios pecados de juventud literarios en los que, además de un "surrealismo provincial y de segunda mano" (Matamoro 176) había demostrado que más que su talento algo desorientado, era la generosa disposición de sus padres la que permitía la publicación, en ediciones de autor, de libros que más tarde serían meticulosamente omitidos de su corpus.

Para algunos escritores conocidos, según lo insinúa Bioy (Borges 7), la tutela de Borges fue decisiva y circulaba la suspicacia de que este último no se había limitado a firmar el elogioso prólogo a La invención de Morel sino que le había "dictado" la novela entera, a la sazón dedicada a Borges. ${ }^{1}$ Lo cierto es que por esa época la amistad de Borges con Bioy y con Silvina Ocampo (1903-1993) atravesaba una edad dorada en la que los tres amigos compartían sus gustos y disgustos literarios en una especie de trinidad simbiótica ${ }^{2}$ que se tradujo en un libro importante por varios motivos: la Antología de la literatura fantástica (1940), cuyo prólogo, firmado a solas por Bioy

\footnotetext{
1 Antes del prólogo a La invención de Morel, Borges ya había abordado críticamente la obra de Bioy Casares en sus reseñas a La estatua casera y Luis Greve, muerto. Ver Borges en Sur $(130,149)$.

2 Juan Rodolfo Wilcock, allegado a los Bioy, habló de la "felicidad mística" de haber conocido a esa "trinidad divina" (Bianciotti 1), aunque también en el Buenos Aires de la época se los conocía como "el trío infernal" (Louis 410). Ver al respecto lo que escribe Bioy Casares en "Libros y amistad" (en La otra aventura, reproducido también como capítulo 15 de sus Memorias) y el minucioso relato de todas las noches en que fue Borges a comer a casa de él y su mujer en las entradas de su diario publicadas bajo el título Borges.
} 
Casares, ofrece algunas pistas teóricas para analizar la obra del propio Bioy -que no cultivó el ensayo ni la teoría como Borges-. La rica variedad que exhibe la antología es a su vez una fuente de apreciable valor para establecer cómo estos tres autores leen lo fantástico, ya que muchos de los textos lanzan reflejos de diferente intensidad en relación con sus respectivas obras.

El prólogo de Borges a La invención de Morel inscribía desde su primera palabra ("Stevenson") la novela de Bioy en una genealogía dilecta: la tradición anglosajona de la literatura fantástica, descalificando en el camino a Ortega y Gasset, a Balzac, a Proust, a "los rusos y los discípulos de los rusos" y anotando en cambio, entre el grupo de los valores positivos, a De Quincey, Chesterton, Dante Gabriel Rossetti, Henry James, Wells y, como excepción no anglosajona, Kafka y Léon Bloy. Lo que articula la argumentación y justifica la división entre "buenos y malos" es en realidad la oposición entre la novela psicológica (que debe ser evitada) y la novela o el relato de aventuras, que para Borges basa su calidad en la perfección de la trama y no sufre de la hipocresía de pretender ofrecer algo veraz o, incluso peor, "real", sino que asume abiertamente su calidad conjunta de artefacto y de artificio.

No es necesario insistir a estas alturas en las preferencias de Borges por esta tradición (Stevenson, Wells, Chesterton, Mark Twain) que a grandes rasgos era considerada buena pero de segunda fila y básicamente dirigida a la juventud, por lo menos en la Argentina de la época -virgen aún del canon Borges-, que sólo podía aceptar como intelectualmente atendible lo que llegaba validado por la cultura francesa (Gombrowicz 45). Tampoco diríamos nada original si nos dedicáramos a apuntar los reparos de Borges a la literatura francesa, que, fuera de algunas notables excepciones, constituyen una extensa lista y son objeto de algunos de sus temibles sarcasmos. ${ }^{3}$ Lo que nos importa es que la influyente lectura de Borges, que logró sin duda el objetivo principal de catapultar al amigo, confinó por algunas décadas la obra de Bioy Casares a un universo literario que, si bien tiene coincidencias con el de Borges, no se corresponde punto por punto con él. Aunque la figura creciente, cada vez más desmesurada de Borges amenazaba sin duda con fagocitar a Bioy, este se mostró capaz de infundir vida propia a sus ficciones, alejándolas paulatinamente de algunos postulados borgianos, y de perfilarse como un lector con gustos personales y en ocasiones distantes de los de su amigo Borges, si bien hacia 1940 sólo parecía una suerte de golem borgeano sin particular iniciativa literaria propia. ${ }^{4}$

3 Sobre el tema, Juan José Saer escribió el ensayo "Borges francófobo" (incluido en su libro El concepto de ficción). También en 2009 se llevó a cabo un coloquio Borges/Francia en la Universidad Católica Argentina, cuyas actas son un vasto catálogo de las idas y vueltas de Borges con la cultura gala (ver bibliografía).

4 Esto se puede apreciar en gran medida a lo largo del diario de Bioy Casares. Así como Silvina Ocampo plantea en sus cuentos una estética en las antípodas de Borges y se revela como una lectora de gustos 
Aunque Bioy mismo se encargaría de esclarecer en diversos reportajes, paratextos y memorabilia muchas de sus inspiraciones, alusiones, homenajes y citas, como es de esperar no agota en dicho contexto las abundantes referencias literarias que solía imbricar en sus ficciones. Frente a esto, la crítica se ocupó en buena medida de señalar fuentes, en un principio todavía aferrada a la genealogía impuesta por Borges y aceptada y divulgada por el propio Bioy. ${ }^{5}$ Luego, poco a poco, los estudiosos de su obra destacarían influencias menos borgianas a medida que la imagen de autor de Bioy lograba desprenderse de él.

De este modo, parece sintomático que una crítica temprana como la de Carlos Mastronardi no logre ver a Bioy sin mencionar al "risueño Bustos Domecq" seudónimo de las aventuras literarias a dúo de Bioy Casares y Borges- y que prácticamente no se mueve de nombres anglosajones como Kipling o el poco conocido poeta victoriano Francis Thompson, mencionado indirectamente a través de su poema más célebre, The Hound of Heaven (Mastronardi 114-5). En su condición de profesor de literatura inglesa de la Universidad de Buenos Aires, un buen lector como Jaime Rest no podía dejar de señalar los hipotextos anglosajones en Bioy Casares. Sin embargo, más allá de las referencias a Donne y a Dunne, su artículo "Las invenciones de Bioy Casares" se concentra precisamente en colocar la obra de este último en una órbita casi exclusivamente borgeana debido a una serie de elementos en común, como la conciencia de la centralidad de los recursos verbales en un texto literario, o una ética narrativa que dote de consistencia y verosimilitud las tramas fantásticas, para señalar por último en qué se aparta Bioy Casares de Borges: “[...] en Bioy Casares se desliza un elemento humano -hasta turbiamente humano, si se quiere- que es presentado con singular comprensión y dramática ironía: nunca están ausentes el amor, el deseo, la angustia ante las acechanzas de destino y de la muerte" (Rest 119). Otra diferencia con Borges es que, para Rest, "hasta la dimensión estrictamente fantástica de los relatos adquiere una peculiar tensión existencial" (120).

Ya con el agudo estudio "Lo arquetípico en la narrativa argentina del 40" Jorge B. Rivera inauguraba una crítica ideológica a Bioy Casares que sería continuada por Blas Matamoro y Andrés Avellaneda. Gracias a la amplia erudición de Rivera en materia de folletines y cultura popular decimonónica, se señala por primera vez, descartando el

independientes frente a la relativa tiranía borgiana, Bioy parece colocarse en un punto equidistante entre las estéticas de Borges y de Silvina Ocampo. Ver Mariano García, "Laberintos y metamorfosis" 77-88. Bioy toma definitiva distancia de Borges con su novela El sueño de los héroes (1954), donde la opción por el "culto del coraje" que Borges defendía en su cuento "El sur" aparece implícitamente criticada. Ver Graciela Speranza "La voz del otro" 285-292.

5 Así, por ejemplo, el prólogo que firma Bioy de la Antología de la literatura fantástica (1940) preparada junto con Borges y Silvina Ocampo, lo muestra como un defensor acérrimo de Wells y un detractor de lo gótico, los castillos, los vampiros, etc. Aun en su sintaxis y en muchos giros verbales se siente la fuerte impronta borgeana. 
obvio precedente de La isla del doctor Moreau (1896), de Herbert George Wells (18661946), a dos autores seguramente innombrables en la galaxia Borges: ${ }^{6}$ el caricaturista francés Albert Robida (1848-1926), autor de coloridas ficciones de anticipación, y Jules Verne (1828-1905), cuya novela Le Château des Carpathes, de 1892, ofrece una serie de elementos que estarán muy presentes en La invención de Morel: el científico creador de homúnculos o espectros y la utilización de recursos tecnológicos para la reproducción de la figura humana (Rivera 129). Otro detalle significativo que pone de relieve Rivera es que las ficciones de Bioy Casares no se inscriben tanto en lo que conocemos como literatura fantástica (con su desestabilizadora carga de vacilación -Todorov- y subversión -Rosemary Jackson-) sino en la tradición de la novela gótica y el relato policial clásico, en las que una realidad alucinante y sobrenatural es desplazada por la introducción de una clave racional que destruye la ambigüedad al reintroducir ciertas categorías de verosimilitud (Rivera 130).

En efecto, esta tendencia racionalista es comentada por Annick Louis en su estudio sobre la Antología de la literatura fantástica. Para Louis, el desacuerdo sobre lo fantástico entre Borges y Bioy ya venía postulado en las reseñas firmadas por Borges a dos títulos de Bioy previos a La invención de Morel: La estatua casera (1936) y Luis Greve, muerto (1937). El conflicto gira siempre en torno a la explicación, que Bioy propone en el prólogo a la antología como eje clasificatorio para organizar el género.

Si los dos primeros puntos de la definición del género fantástico sugieren que se trata de una función que el texto asume, "Los que se explican por la agencia de un ser o de un hecho sobrenatural/Los que tienen una explicación fantástica pero no sobrenatural" (Bioy Casares, "Prólogo" 7), en el tercero se supone que es el lector el que está en juego ("Los que se explican por la intervención de un ser o de un hecho sobrenatural, pero insinúan también la posibilidad de una explicación natural -'Sredni Vashtar', de Saki-; los que admiten una explicativa alucinación"), confundiendo el papel que juega la explicación en la literatura fantástica. Louis señala acertadamente que la diferencia entre textos que proponen una explicación de los acontecimientos fantásticos y aquellos que no lo hacen no está estudiada por Bioy y que de hecho la segunda posibilidad -la ausencia de explicación- queda excluida teóricamente, ${ }^{7}$ pese a que muchos cuentos de la antología son de ese tipo, incluidos los relatos de Borges y de Silvina Ocampo; en el primero porque la acumulación de explicaciones hace que

6 En el ensayo "El primer Wells" (en Otras inquisiciones, de 1952) la comparación entre Wells y Verne da pie a Borges para demostrar lo que según él es la profundidad del primero frente a la chatura del segundo, al que descarta como "un jornalero laborioso y risueño" (Borges, Obras Completas 697).

7 La concepción misma de "explicación fantástica" tiene algo de oxímoron si consideramos lo auténticamente fantástico como carente de explicación. La clasificación que propone Bioy es algo confusa, y no extraña que en una posdata a la edición de 1965 diga que "en aquel prólogo hay afirmaciones de las que siempre me he arrepentido" (13). 
estas se desmientan unas a otras, y en la segunda porque su estética general es reacia a cualquier tipo de explicación o racionalización (Louis 414-5).

Un estudio que amplía notablemente la red de hipotextos en lo que la propia autora denomina novelas-isla (La invención de Morel, Plan de evasión, 1945) es la Guía de Bioy Casares de Suzanne Jill Levine, lectora perspicaz que además conoce de la obra de Bioy en calidad de traductora de su obra al inglés. A la tradición del gótico y el policial apuntada por Rivera, Levine agrega lo pastoril, a la luz de lo caracterizado por Northrop Frye como romance en The Secular Scripture: una tradición genérica algo proteica que incluye aspectos del relato de aventuras, la ficción gótica, el idilio pastoril y los escritos utópicos. El aporte de Levine es la meticulosa demostración de la relación intertextual e irónica que mantiene la primera novela con la segunda, pero resulta al mismo tiempo un valioso catálogo de algunas de las lecturas que inciden en estos primeros textos de Bioy Casares.

Si bien Levine destaca principalmente las lecturas anglosajonas menos obvias (como la de la antropóloga Alexandra David-Neel para la creación de los espectros de La invención de Morel, la de The Croquet Player de Wells o la de Uthopia de Thomas More) no deja de señalar la importancia de Jules Verne (aunque ella sólo menciona la posible influencia de La isla misteriosa), la de Gaston Leroux y la de otro autor francés entrañable para Bioy y que merece mayor atención en el estudio de sus fuentes: Paul-Jean Toulet (1867-1920). Asimismo otorga importancia a la tradición grecolatina, desde el tratado sobre Isis y Osiris de Plutarco hasta las Metamorfosis de Ovidio. Como apéndice, el libro incluye una "auto-cronología" en la que el propio Bioy se explaya abundantemente sobre sus lecturas.

Con la publicación en el año 2012 de la Obra completa I al cuidado de su albacea y editor de textos póstumos, Daniel Martino, se aclaran algunas dudas más en las eruditas notas a los textos de Bioy publicados entre 1940 y 1958. Gracias a que Martino ha tenido acceso no sólo a la biblioteca de los Bioy sino a la correspondencia y al diario completo de este último, nos va revelando lo que quizás sean los últimos enigmas intertextuales de la narrativa de Bioy Casares. Así, por ejemplo, apunta que Morel era el apellido de la esposa de Verne, y a continuación resume los detalles significativos de El castillo de los Cárpatos (Bioy Casares, Obra Completa I 687). Aunque algunas de sus notas dependen en cierta medida de lo ya apuntado por Levine y otras son innecesarias o demasiado aventuradas, Martino trae a colación, a propósito de La invención de Morel, un texto inusitado de Apollinaire, "Le toucher à distance", del volumen de 1910 L'Hérésiarque et $C^{i e}$ (693), establece como posible inspiración del apellido del científico de Plan de evasión la personalidad del jesuita Louis Bertrand Castel (1688-1757), inventor de un clavicordio cromático (700) y menciona textos inesperados, como el relato "The Stratagem" (1929) del funambulesco Aleister Crowley (1875-1947), u otros poco conocidos de William Somerset Maugham (18741965). 
Frente a tanta erudición no es mucho lo que se puede agregar, y acaso tampoco sea necesario agotar hasta la última referencia o guiño de textos plagados de ambas cosas. Sin embargo, puede resultar de utilidad señalar algunos puntos y agregar algunos autores que enriquecen la red de lecturas, no para demostrar de manera irrefutable que Bioy leyera a un autor u otro, tampoco para poner en evidencia acusadoramente las omisiones de sus lectores más influyentes, sino más bien para proponer nuevos elementos a esta genealogía con la cual la crítica comenzó a ampliar la establecida inicialmente por Borges. Esto tal vez nos ayude a percibir cómo se (re)ubica la obra de Bioy Casares en el canon de la literatura fantástica y a recorrerla desde nuevos caminos.

A la manera del ensayo de Borges "Kafka y sus precursores", el descubrimiento o la profundización de determinadas fuentes en Bioy Casares debería no sólo enriquecer su obra sino la de los autores previos que aparecen en ella como en un palimpsesto: más allá del individuo Bioy Casares, puesto que "nada importa la identidad o la pluralidad de los hombres" (Borges, Obras Completas 712), importa en cambio el diálogo intertextual que se pueda detectar. Así como percibimos el matiz de lo kafkiano en la paradoja de Zenón, que nunca leyó a Kafka, del mismo modo creo que puede ser útil buscar lo "bioycasariano", aun en precursores sobre los que no nos consta la frecuentación de Bioy Casares. Otro aspecto para tener en cuenta es que las influencias o rasgos que encontramos no siempre son de orden temático, sino a veces, como se señalará, estructural.

En primer lugar, sobre el ya mencionado Paul-Jean Toulet, poeta especialmente apreciado por Bioy a causa de su procedencia del Béarn, la misma región francesa de la familia paterna de Bioy, tanto Levine como Martino destacan su obra más conocida, las poesías póstumas de Les contrerimes (1921), de donde proviene seguramente el nombre de Faustine, la mujer imposible que enamora al narrador protagonista de La invención de Morel. Sin embargo hay otro texto de Toulet que pudo influir en la calidad irónica que, sutilmente en las notas del "editor" de La invención de Morel y más abiertamente en los comentarios de Antoine Brissac a la correspondencia de su sobrino en Plan de evasión, imponen una distancia entre el lector y la materia narrada. Me refiero a la novela Monsieur du Paur. Homme public (1898), en donde la relación entre el editor y el material presentado (la vida del personaje del título, cuyo apellido es homónimo de porc) aparece llena de intervenciones que destruyen la ilusión de inmediatez de las ficciones realistas decimonónicas.

La complejidad estructural de Plan de evasión es sin dudas deudora de la igualmente compleja Monsieur du Paur, presentada por un "editor" que desconfía de la biografía que sobre M. du Paur escribe su colega Douville, de modo que entre las notas contradictorias de uno y otro y el verdadero M. du Paur, imposible de conocer pero que se adivina mucho menos moral que el retrato sentimental que de él hace Douville, se multiplican los planos y se produce un efecto irónico de distanciamiento. 
La presencia constante de Toulet en la vida de Bioy queda atestiguada en sus diversas memorabilia, si bien no parece haber mencionado esta novela, cuya estructura "de sospecha" participa de esa corriente modernista de narradores no confiables que ha estudiado Wayne Booth en The Rhetoric of Fiction y que va de Henry James a Nabokov. La ironía que necesariamente se desprende de este juego de alejamientos y la multiplicación de instancias narrativas también influye en el tratamiento, por parte de Toulet, de su tema: la irrisión burguesa que tanto explotaría Bioy Casares a partir de El sueño de los héroes (1954) en adelante y que compendió en su Diccionario del argentino exquisito (1971). Asimismo la práctica del centón (tomar elementos de otras obras literarias para que reacomodados formen un texto nuevo), que Toulet exhibe en su novela con frases de Stendhal y de Arthur Machen, y la invención de aforismos será también práctica habitual en Bioy Casares. ${ }^{8}$

Aunque Bioy Casares, en conversación con Suzanne Jill Levine (212) recuerda haber leído de Verne La vuelta al mundo en ochenta días, Un viaje a la luna, 20.000 leguas de viaje submarino y su secuela La isla misteriosa (novela de 1874 que Levine considera significativa para el análisis de las dos novelas-isla) no puede soslayarse la importancia de la mencionada El castillo de los Cárpatos (1892) en la configuración de una mujer-imagen misteriosa, inalcanzable y deseada, en la creación de un científico genial pero fáustico y enloquecido y por sobre todo esto en la estructura de misterio de insinuaciones sobrenaturales y resolución racional. Si bien la historia de Verne es bastante elemental en el plano temporal, ya que, como lo sugiere su título de promesas góticas, la atención se concentra de antemano en el espacio, debemos agregar que la proliferación de planos temporales ya se presenta en el cambio de paradigmas de L’horloge de siècles (1902) de Robida, donde a causa de un cataclismo cósmico la tierra comienza a girar al revés y el tiempo transcurre para atrás. De Albert Robida vale destacar también la ausencia del didactismo que lastra las ficciones de Verne, más aquello que Arthur B. Evans denomina "heterogeneidad hermenéutica", es decir la intrusión, sin particular influencia en la trama, de una variedad de acontecimientos mundanos en la vidas de los protagonistas, la polifonía y la hibridez, que lo convierten en un eslabón entre Verne y Wells (Evans, "Introducción" xxiv-xxv), una forma intermedia que a despecho del juicio de Borges podría aplicarse también a las ficciones de Bioy en su combinación de Verne y Wells.

Esta línea de la ciencia ficción fantástica francesa puede decirse que llega a su exasperación en un complejo discípulo de Verne: Raymond Roussel (1877-1933). De Bioy se comentó en alguna parte su antipatía por Roussel, ${ }^{9}$ y no nos consta en

8 No sólo en Morel y Plan aparecen sutilmente distorsionadas diversas citas, sino que además Bioy publicará años más tarde De jardines ajenos, libro enteramente compuesto de citas.

9 "A Bioy Casares no le gusta, o no le gustaba, Raymond Roussel", José Bianco en conversación con Danubio Torres Fierro, en Ficción y reflexión (401). 
forma concluyente que a la hora de escribir la novela que afirmaría su lugar en el campo literario conociera a este autor, ${ }^{10}$ pero hay algunas similitudes que señalar. En Roussel la divisa es la invención absoluta, y son recurrentes complejísimos aparatos o construcciones que a simple vista (es decir, a partir de una descripción) no se entienden; es necesaria la ayuda de los "antecedentes", que siempre proveen la explicación. Si no en espíritu, ni en sensibilidad, y menos en su extremismo, la primera novela de Bioy Casares no deja de ser la exposición de un misterio encerrado en un aparato y luego su extensa explicación; es, de manera velada o puramente casual, una máquina de escritura rousseliana. Herencia de su idolatrado Verne, en Roussel también son habituales los científicos un poco locos así como los lugares del exotismo y la colonización decimonónicos (África, Cuba, la Guyana francesa -Plan de evasión, se ambientará en Cayena-).

Por supuesto que la escritura de Bioy Casares no parte del complicado procedimiento de homofonías de Roussel, como tampoco los resultados son los mismos. Pero así como Bioy ha confesado interesarse en Conrad no por su escritura, a la que considera decorativa y alambicada, sino por sus temas, ${ }^{11}$ existe la posibilidad de que con Roussel le haya ocurrido lo contrario. La presencia desembozada de lo mecánico en Roussel tal vez haya alarmado a Bioy, que pudo ver reflejada en esa escritura sus propias tendencias, que más tarde se empeñó en corregir haciendo uso de la "heterogeneidad hermenéutica". En tal caso quizá sería más apropiado hablar de Roussel como contra-fuente en la obra bioycasariana en el nivel semántico y como fuente en el nivel estructural. En la percepción estética de Bioy, el aparato se confunde con lo aparatoso que debe ser evitado, erradicado, y después de las novelas-isla cambiará enfáticamente de rumbo:

[...] cuando apareció Plan de evasión, me atacaron porque las dos novelas [ésta y La invención de Morel] eran demasiado racionales; eran como una literatura inspirada en la relojería, y decían que yo estaba como alejado de los sentimientos del prójimo o del ser humano. Entonces me pareció que la crítica era atinada y que yo ya había

${ }_{10}$ En su reseña al libro The Spirit of Chinese Poetry (Sur, $\mathrm{n}^{\circ} 86$, noviembre de 1941) Bioy menciona a Roussel en una nota al pie junto con Joyce, aunque sólo se refiere -al parecer de manera irónica- a su poesía - que de todos modos es tan narrativa como su prosa-. En el Borges (2006) de Bioy hay una alusión a Roussel pero bastante más tarde, el 19 de noviembre de 1963, donde Borges y Bioy deciden cambiar a Roussel por Abramowicz -el amigo de Borges en Ginebra- como confidente de César Paladión en el cuento escrito a dúo "Homenaje a César Paladión" (Crónicas de Bustos Domecq, 1967). Impressions d'Afrique, quizá el texto más importante de Roussel, fue traducido al español en 1973 por Estela Canto, amiga de Borges y Bioy Casares.

11 En Bioy Casares a la hora de escribir, cuando le preguntan sobre una posible influencia de Conrad dice ABC: "Sí, pudo tenerla en la construcción de algunos de sus relatos, como La línea de sombra, pero no precisamente en el estilo. Yo no quiero escribir de un modo ornamental" (22). 
aprendido lo suficiente en la profesión de escritor para atreverme a hacer un poco de psicología y tratar de que mis personajes fueran más reales. (Sorrentino 113)

Plan de evasión es curiosamente parecida a su novela precedente en algunos aspectos: la isla, el científico loco ahora llamado Castel, el experimento fáustico; pero con una estructura general más barroca y complicada. Es en cierto modo -en cierto modo arriesgado que no entusiasmó a los lectores tanto como la primera- una novela gemela de La invención de Morel, aunque como todo gemelo, conserva su identidad. También como en la primera, aquí hay un texto previo obliterado por la referencia culta -siempre, o todavía, borgeana-. La referencia culta es William James ${ }^{12}$ (18421910), el hermano de Henry, el corresponsal de Macedonio Fernández, el filósofo que enseñaba el padre de Borges en sus clases... El modelo silenciado no pertenece en este caso a la novela de aventuras sino al relato de terror y se trata de un texto que a la sazón Toulet tradujo al francés: "The Great God Pan" (1894) de Arthur Machen (1863-1947), autor que si bien no parecía desagradar ni a Borges ni a Bioy (este último hubiera debido rescatarlo al menos por traducir al inglés las memorias de Casanova), no figura en la Antología de la literatura fantástica y es duramente descalificado en una conversación privada. ${ }^{13}$ Mencionemos de paso que Toulet preparaba su traducción de Machen mientras redactaba Monsieur du Paur, en donde cita fragmentos literales del relato de Machen y lleva a cabo un pastiche de este en el que carga las tintas sadomasoquistas apenas sugeridas en el original (Toulet 161-179).

El proyecto de Castel, que consiste en intervenir cierta zona del cerebro para modificar las sensaciones de los presos que tiene bajo su supervisión, remite a la primera sección del relato de Machen ("El experimento"), donde un médico, el doctor Raymond, interviene mediante cirugía menor el cerebro de una joven para que ésta

${ }^{12}$ En Bioy Casares a la hora de escribir (100) Bioy aclara que fue la lectura de los filósofos ingleses Berkeley, Hume- la que lo llevó a crear ese argumento. Queda pues fuera de la lista prestigiosa -en una novela que abunda en referencias filosóficas y literarias- Arthur Machen. A juzgar por las notas de Martino (696, 711-712) la teoría de William James que despliega Castel es citada a partir del libro de Bertrand Russel The Analysis of Mind de 1921.

${ }^{13}$ Borges, no obstante, incluyó en la colección Biblioteca Personal la novela de relatos intercalados Los tres impostores de Machen, a la que comenta en un prólogo. En el Borges de Bioy se lee en la entrada del 16 de julio de 1967. "Bıoy: 'Empiezo a sospechar que Arthur Machen era un pelafustán y un latero'. BORGES: 'Sin una sola idea en la cabeza'. BIOY: 'Con la sola idea de esos hombres antiguos y hostiles, que sobreviven en nuestra civilización. Se lo vio como discípulo de Stevenson, muy inferior a Stevenson: una imagen poco favorable para la fama'. BORGES: 'Stevenson inventó ese Londres misterioso, fabuloso, pero en broma, con Florizel de Bohemia y el club de los suicidas. Machen retomó esa idea, pero la usó para dar miedo. La volvió barata y ridícula'. BIOY: 'Quizá el origen de esa idea sobre Londres está en De Quincey. Como De Quincey, Machen es digresor y romántico, pero sus digresiones aburren y su romanticismo es de mala calidad. Tal vez todo romanticismo sea de mala calidad. La mala calidad en Machen es demasiado evidente"”. 
pueda percibir una nueva dimensión que según él existe pero es inaccesible a nuestros sentidos, ya que nuestras percepciones, cubiertas por un velo, son incapaces de conocer el mundo real (Machen 10). En ambos casos el resultado del experimento es similar: la muchacha del cuento de Machen queda reducida a un estado de cretinismo, en tanto que los presidiarios de Castel y Castel mismo (que al igual que Morel se somete a su propio experimento) se comportan como hombres mentalmente mutilados. La importante diferencia estructural es que en el texto de Machen el experimento es referido al comienzo, constituye su prólogo, en tanto que en Bioy la trama se organiza, como en La invención de Morel, primero presentando datos en sí mismos insignificantes luego validados y fijados por la densa explicación, que funciona como epílogo. En ese sentido, el texto de Machen es auténticamente fantástico (una dimensión paralela parece haberse colado en nuestra realidad) en su progresión de lo racional/científico hacia lo irracional, en tanto que el de Bioy, inversamente de lo irracional a lo racional, recala en la estructura gótico/policial ya comentada.

Como suele ocurrir con las invenciones de Roussel, en Plan de evasión encontramos un paisaje habitado por personas cuyos movimientos incomprensibles, mecánicos, vagamente siniestros, sólo se comprenderán con la revelación del experimento. Hay en realidad un desplazamiento: los experimentos con animales del inexorable Moreau de Wells aparecen en realidad en Plan de evasión. Si como dice Suzanne Jill Levine (1982 74-5) Bioy opera en Morel una metamorfosis sobre las metamorfosis que crea Moreau -metamorfosis en primer lugar nominal a partir del desvío - au a - $l$ y luego temática, pues lo que hace la máquina de Morel es transformar humanos en imágeneshay también una puesta en abismo que vuelve aun más barroca la construcción de Plan de evasión comparada con La invención de Morel: la intención de Castel, con su intervención en el aparato perceptivo de sus presidiarios, es crearles la ilusión de que cada uno tiene una isla para sí; ilusión como mínimo extraña, si no paradójica, puesto que los presos se encuentran ya en una isla. Más que puesta en abismo - una alusión al relato dentro del mismo relato - tal vez habría que hablar de una serie de inclusiones por decirlo de algún modo transdiegéticas y metalépticas: la isla de Morel contiene en germen las tres islas de Castel que contienen a su vez las islas mentales de los presidiarios.

Plan de evasión es una apuesta redoblada de La invención de Morel: su compleja estructura -el diario de Nevers comentado por su tío y entrecruzado por otras voces y documentos- aspira ilusoria o perversamente a una polifonía en sentido bajtiniano, pero es precisamente ilusoria esta polifonía ya que hacia el final el lector comprende que hay un manejo sesgado de la información, hay intereses familiares de por medio que escapan a la perspectiva de Nevers y que sellan trágicamente su aventura.

En un cuento que aparece en la colección de su siguiente título, La trama celeste (1948), el progreso científico se presenta en clave darwiniana. En "De los reyes 
futuros" el narrador -cuya trayectoria inicial remite claramente a Samuel Butler-, ${ }^{14}$ se las ingenia en su calidad de espía para irrumpir en la quinta (en cuyo parque una estatua de Fedro, el fabulista latino, representa un indicio tan evidente como lo será más tarde el nombre Samaniego en Dormir al sol, 1973) en la que sus amigos de infancia Marcos y Helena llevan a cabo misteriosas actividades. La revelación en boca de Marcos no tarda en producirse:

¿Recuerdas nuestro entusiasmo cuando descubrí a Darwin? ¿La infinidad de libros sobre la evolución que leí en pocos días? Muy pronto concebí esta esperanza: la evolución impuesta a una especie, a través de milenios, por la ciega acción de la naturaleza, podría lograrse en pocos años, por una acción deliberada. El hombre es un resultado provisorio en una senda evolutiva. Hay otras sendas: las de otros mamíferos, la de los pájaros, la de los peces, la de los anfibios, la de los insectos... [...] nuestra obra maestra son las focas. Hemos torturado animales jóvenes -para determinar qué podía conseguirse de una atención siempre despierta-, hemos actuado sobre células y embriones, hemos comparado los cromosomas de los fósiles congelados de Siberia. Pero no era suficiente obrar sobre individuos, debíamos establecer costumbres genéticas. (Bioy Casares, Trama Celeste 36)

El resultado de estos complejos y una vez más fáusticos experimentos son diversos mutantes: orugas con "rostros casi humanos" (Trama Celeste 34) y focas con poder telepático que tienen sometidos a los científicos que alguna vez las sometieron a ellas. Además del tema de la tortura de animales con fines científicos, presente en Wells e incluido en Plan de evasión, el recurso a Darwin sirve para demostrar que una alteración en el elemento de azar que presupone la teoría de la evolución podría crear animales inteligentes. Pero la elección que hace el autor, tomando a la foca como epítome de esta posibilidad evolutiva, adelanta una intención burlesca ${ }^{15}$ que hacia el desenlace pone en ridículo el experimento, sugiriendo un grotesco fracaso científico. Una vez más, como la máquina de Morel y las intervenciones de Castel, la elaborada y sofisticada hipótesis científica da como resultado la muerte, la ruina o la destrucción. En ese sentido podemos observar en Bioy Casares una constante reacción al progreso

14 Este autor inglés se instaló de joven en Nueva Zelanda, donde hizo una aceptable fortuna como ganadero que le permitió volver a su tierra emancipado de su tiránico padre. En la vertiente de polémica científica su obra cuestiona aspectos de la teoría de Darwin en Evolution, Old and New (1879) y Unconscious Memory (1880). El narrador del cuento de Bioy se embarca para Australia, donde es administrador de un establecimiento rural (Bioy Casares, Trama Celeste 28). En el Borges de Bioy hay numerosas alusiones, siempre elogiosas, a Butler. En diversas ocasiones Bioy alaba sin reparos los Note-books de Butler, junto con Boswell uno de los modelos de sus propias anotaciones privadas.

15 La foca carece de la nobleza que los occidentales adjudican al perro o al caballo, o de la belleza y misterio de los felinos; de hecho, la primera alusión a las focas en este cuento se produce en un circo. Recordemos de paso que en la Odisea Proteo, epítome de las metamorfosis, habita entre focas. 
científico puesta en evidencia por el permanente subtexto fáustico, y que aparece precisamente tratada por el anti-darwiniano Samuel Butler con ambigua ironía en sus dos novelas utópicas, Erewhon (1872) y Erewhon Revisited (1901), donde el lugar del título, anagrama de Nowhere, presenta una sociedad que ha prohibido el desarrollo de las máquinas, que amenazaban con usurpar la supremacía humana y que habían conducido a una guerra civil.

Ahora bien, si nos concentramos en un cultor de lo fantástico más cercano, Leopoldo Lugones (1874-1938), veremos que tanto en Las fuerzas extrañas (1906) como en su única novela, El ángel de la sombra (1926), el saber científico está representado por hombres que tarde o temprano muestran el sesgo siniestro, en contacto con la oscuridad y con el mal: la ciencia es una "idea fija", animada por una fuerza no menos extraña que la de los fenómenos paranormales, capaz de desencadenar tragedias, justificar crueldades y aun conductas criminales. Con estos científicos, tan alejados de los más benévolos de Roussel, en quienes la ciencia es creativa e incluso luminosa, ${ }^{16}$ Lugones forja el molde sobre el que Bioy volverá, primero asumiendo la gravedad del modelo lugoniano en Morel y Castel, para luego ensayar variaciones más irónicas como la de los esclavos de las focas ya mencionados, o el doctor Samaniego de Dormir al sol, pero donde, pese a la ironía y el humor, los científicos o médicos no pierden su aura ominosa o desquiciada.

Con Dormir al sol llegamos al final del recorrido de la tradición francesa en la obra de Bioy Casares, pues con sus delirantes trasplantes de órganos entre hombres y animales reaparecen algunos elementos tratados en todos sus posibles narrativos por Maurice Renard (1875-1939) en Le docteur Lerne, sous-dieu, novela de 1908 dedicada a H. G. Wells. El médico del título es otro científico loco que no duda en utilizar a su sobrino como objeto de sus experimentos, que consisten básicamente en lo que él llama "intervención de personalidades humanas" (Renard, Le Docteur 157) a través de intercambios de cerebro inspirados en sus experimentos con injertos vegetales y animales. Como en Plan de evasión, en la novela de Renard aparece transcripto el diario con los experimentos de Lerne, fáustico inventor que con su sistema de intercambios pretende asegurar la inmortalidad del hombre sobre la base del asesinato.

En la novela de Bioy de 1973 se produce una yuxtaposición de dos vertientes: volvemos al científico loco y a los experimentos con hombres y animales, pero ahora

\footnotetext{
${ }^{16}$ Asimismo, en Horacio Quiroga o en Roberto Arlt, la asumida personalidad del inventor puede plantear una promesa no sólo de progreso sino de promoción social. Hay, evidentemente, una sobredeterminación ideológica en la matización del progreso científico. V. la primera parte de La imaginación técnica de Beatriz Sarlo. La operaciones que se llevan a cabo en Dormir al sol traen vagamente a la memoria aquellas de La ciudad de los locos, de Juan José de Soiza Reilly, donde la condición médico-científica resulta más ambigua. Por otra parte, el método de "curación de almas" del doctor Reger Samaniego podría ser una alusión malintencionada al psicoanálisis (Dormir al sol 233).
} 
nos encontramos en un barrio típico de Buenos Aires, Villa Urquiza, y su narrador, Lucho Bordenave, es un relojero sin demasiadas luces bastante alejado de los narradores de las novelas-isla, que eran o decían ser escritores. Sin embargo, el lector atento recordará que Bordenave es el verdadero apellido de quien en Plan de evasión aparecía bajo el seudónimo de Dreyfus, con lo cual hay una intención sutil de vincular intertextualmente ambas novelas.

Dormir al sol puede leerse como una reducción paródica y doméstica de las novelas-isla, una trasposición en clave de sainete criollo de las graves situaciones planteadas anteriormente. Bordenave está casado con Diana, una mujer de mal carácter con todos los trazos que el discurso machista designaría figuradamente como una "loca". Pero como en la tradición de la literatura fantástica, hay un deslizamiento de lo figurado a lo literal, y tras una serie de enredos Diana termina internada en el instituto frenopático del ridículo doctor Reger Samaniego. Según la teoría de este médico, no hay mejor cura de reposo para los nervios alterados que una "inmersión en la animalidad" (Bioy Casares, Dormir al sol 234), para lo cual trasplanta cerebros humanos en cuerpos de perros, con la particularidad de que Reger Samaniego no se refiere a términos como "cerebro" o "mente" sino a "alma".

Además de la referencia a Stevenson (The Body Snatchers, aludida como una serie de televisión con el melodramático título de Borrasca al amanecer, Dormir al sol 228), es evidente que Bioy lleva a cabo una inversión paródica de La isla del doctor Moreau de Wells. Si Moreau intentaba humanizar a los animales, Reger Samaniego animaliza a los hombres. Pero los argumentos del doctor Samaniego son curiosamente parecidos a los que plantea Lerne: ${ }^{17}$

Experiencias antiguas [se lee entre las notas del doctor Lerne] han demostrado que todo cuerpo posee un alma. Pues el alma y la vida son inseparables, y todos los organismos, entre su nacimiento y su muerte, gozan de un alma más o menos desarrollada, según estén ellos mismos mejor o peor organizados. Así, del hombre al musgo pasando por los pólipos, cada ser vivo tiene su propia alma. (¿Acaso las plantas no duermen, no respiran, no digieren? ¿Por qué no habrían de pensar?). Esto demuestra que hay un alma allí donde no hay cerebro. Así, el alma y el cerebro son independientes uno de otro. Por consiguiente, las almas deben poder intercambiarse entre ellas, sin que intervengan para ello los cerebros. (Renard, Le Docteur 188, traducción mía)

${ }^{17}$ La novela más famosa de Renard, Les mains d'Orlac (1920), insiste en los trasplantes y presenta algunos elementos que parecen anticiparse a La invención de Morel, como las presencias espectrales producidas por una ilusión óptica denominada "escotoma" (Renard, Les mains 238). Maurice Renard, significativamente, rechazaba la tradición francesa de lo que denominaba "novela científico maravillosa" (Robida, Verne) y reconocía como su maestro sólo a Wells. Ver Evans, 1994 y Renard, 1994. 
El sobrino del doctor, narrador de esta novela, es también víctima de su tío y termina convertido en toro, así como al final de Dormir al sol Bordenave acaba en el cuerpo de un mastín atigrado. ${ }^{18}$

Si en la novela de Renard siempre se habla claramente de cerebros y almas por separado, en la de Bioy parece repetirse la concepción de una esencialidad concentrada en el alma, como lo sugiere este diálogo: "El alma de la señora estaba muy enferma", dice el médico, a lo que Bordenave replica: "Tengo entendido que la ciencia niega el alma".

-La ciencia progresa un paso adelante y un paso atrás. Existe el alma y existe el cuerpo, exactamente como lo afirmaban los viejos libros. Hoy por hoy lo hemos comprobado. La medicina encontró el remedio para algunas enfermedades del cuerpo (poquísimas, ya lo sé); en cuanto a las enfermedades del alma... (233)

Los puntos suspensivos claramente podrían remplazar a la disciplina que intentó curar las "enfermedades del alma", el psicoanálisis, y el grotesco método de Reger Samaniego podría ser una maligna alusión a ello. El doctor Samaniego ha seguido la teoría de Descartes (característicamente dualista) de que el alma se encuentra en una glándula del cerebro y de que es posible aislarla (Bioy Casares, Dormir al sol 237-8).

En la obra de Bioy Casares hay un tratamiento progresivamente paródico y deformante de los científicos que pretenden aplicar sus teorías: la relación intertextual entre Morel y Castel es deliberada. En cambio Reger Samaniego, que aparece previamente como autor de varias entradas ridículas en el Diccionario del argentino exquisito, combina aspectos de sabio loco de ciencia ficción con rasgos de embaucador profesional y sus motivos filantrópicos no aparecen tan claros ni son tan dramáticos como los de sus predecesores.

En conclusión, tras un breve repaso por la crítica, observamos que más allá de ciertos detalles psicológicos y realistas destinados a disimular la cualidad racional de tramas muy elaboradas, el mundo de Bioy Casares es un mundo cerrado a la realidad (Rivera, "Lo arquetípico" 141; Matamoro, Oligarquía 177) que depende de la invención y de la intertextualidad, elementos que a su vez se entrelazan de manera estrecha. Es por ese motivo que aun hoy no se agotan las ricas alusiones diseminadas en sus textos, ni tampoco los ecos de obras no citadas velada o expresamente por Bioy, pero que imponen su presencia por algo que podríamos denominar inercia genérica: la del género fantástico y sus fronteras siempre móviles.

${ }_{18}$ En la novela de Renard, el narrador recupera su cuerpo humano tras la peripecia animalizante. En el caso de Bioy, la narración de Bordenave se interrumpe y el epílogo corre por cuenta del narratario de la historia, que es quien hace referencia al mastín. 


\section{BiBLIOGRAFÍA}

Bianciotti, Héctor. "La felicidad del poeta" [sobre J. R. Wilcock]. La Nación (4-II1998).

Bianco, José. Ficción y reflexión. Una antología de sus textos. México: FCE, 1988.

Bioy Casares, Adolfo. La invención de Morel. Buenos Aires: Colihue, 1985.

Plan de evasión. Barcelona: Destino, 2006.

La trama celeste. Buenos Aires: Losada, 1990.

"Prólogo" y "Posdata". Antología de la literatura fantástica. Buenos Aires:

Sudamericana, 1965.

Dormir al sol. Buenos Aires: Emecé, 1973.

Bioy Casares a la hora de escribir. Esther Cross y Félix della Paolera, eds.

Barcelona: Tusquets, 1988.

Memorias. Infancia, adolescencia y cómo se hace un escritor. Barcelona:

Tusquets, 1994.

Descanso de caminantes. Diarios intimos. Buenos Aires: Sudamericana, 2001. Borges. Buenos Aires: Destino, 2006.

Obra completa I (1940-1958). Daniel Martino, ed. Buenos Aires: Emecé, 2012.

Borges, Jorge Luis. Obras Completas. Buenos Aires: Emecé, 1974.

Borges en Sur. 1931-1980. Buenos Aires: Emecé,1999.

Cámpora, Magdalena y Javier González, eds. Borges-Francia. Buenos Aires: Facultad de Filosofía y Letras de la Universidad Católica Argentina, 2011.

Evans, Arthur B. "Introduction". Twentieth Century. Albert Robida, ed. Middleton: Wesleyan UP, 2004.

"The Fantastic Science Fiction of Maurice Renard". Science Fiction Studies XXI/64, part 3 (November 1994).

García, Mariano. "Laberintos y metamorfosis: estéticas en tensión en Silvina Ocampo y Jorge Luis Borges". Amaltea, Revista de mitocrítica 1 (2009).

"Sobre la parábola dualista en la obra de Adolfo Bioy Casares". Actas del XXXIX

Congreso del Instituto Internacional de Literatura Iberoamericana, Universidad de Cádiz, 2012.

Gombrowicz, Witold. Diario argentino. Buenos Aires: Adriana Hidalgo, 2001.

Levine, Suzanne Jill. Guía de Adolfo Bioy Casares. Madrid: Fundamentos, 1982.

Louis, Annick. "Definiendo un género. La Antología de la literatura fantástica de Silvina Ocampo, Adolfo Bioy Casares y Jorge Luis Borges". Nueva revista de filología hispánica XLIX/2 (2001).

Machen, Arthur. "El gran dios Pan". Antología de cuentos de terror 3. De Arthur Machen a H. P. Lovecraft. Rafael Llopis, ed. Madrid: Alianza editorial, 1982.

Matamoro, Blas. Oligarquía y literatura. Buenos Aires: Ediciones del Sol, 1975. 
Mastronardi, Carlos. "La trama celeste". Ficciones argentinas. Antología de lecturas críticas. Buenos Aires: Norma, 2004.

Renard, Maurice. Le Docteur Lerne, sous-Dieu. Paris: José Corti, 2010. Les Mains d'Orlac. Paris: Plon, 1933.

"On the Scientific-Marvelous Novel and Its Influence on the Understanding of Progress". Science Fiction Studies XXI/64 (1994).

Rest, Jaime. "Las invenciones de Bioy Casares". Ficciones argentinas. Antología de lecturas críticas. Buenos Aires: Norma, 2004.

Rivera, Jorge B. "Lo arquetípico en la narrativa argentina del 40”. Ficciones argentinas. Antología de lecturas críticas. Buenos Aires: Norma, 2004.

Roussel, Raymond. Impresiones de África. Estela Canto, trad. Buenos Aires: De la Flor, 1973.

Sarlo, Beatriz. La imaginación técnica. Sueños modernos de la cultura argentina. Buenos Aires: Nueva Visión, 1997.

Sorrentino, Fernando. Siete conversaciones con Adolfo Bioy Casares. Buenos Aires: E1 Ateneo, 2001.

Speranza, Graciela. "La voz del otro: Bioy Casares y Silvina Ocampo". Homenaje a Adolfo Bioy Casares. Alfondo De Toro y Susanna Regazzoni, eds. Frankfurt: Vervuert, 2002.

Toulet, P.-J. Monsieur du Paur. Homme public. Paris: Émile-Paul Frères, 1920.

Verne, Jules. Le Château des Carpathes. Paris: Le Livre de Poche, 1966. 